\title{
Radionuclide Sensors for Subsurface Water Monitoring FINAL REPORT
}

Principal Investigators: Jay W. Grate, Ph.D. Pacific Northwest National Laboratory

Timothy A. DeVol, Ph.D. Clemson University 


\section{INTRODUCTION}

Of all the contaminants on DOE sites, radionuclides are the most vexing and those for which DOE owns unique responsibility (i.e. the DoD and industry do not have these contaminants and are not developing independent solutions). Typically, water samples are collected and transported to an analytical laboratory, where costly radiochemical analyses are performed with sample turnaround times of weeks to months. To support field studies, model validation, remediation activities, and long term stewardship, radionuclide sensors are needed for use at-site or in situ to provide more frequent and less costly data on radionuclide levels and migration. However, no radionuclide sensors existed for groundwater monitoring prior to this team's research under the EMSP program.

Nongamma-emitting contaminants present significant fundamental challenges for detection and identification in the field. The $\beta$ and especially $\alpha$ particles are characterized by short ranges and rapid energy dispersion in condensed media. Furthermore, the energy spectra generally do not provide adequate selectivity on their own. In addition, these contaminants must be determined to extremely low detection limits set by regulatory requirements. Therefore, preconcentration and separation methods and long signal accumulation or counting times are necessary.

In this EMSP work, PNNL and Clemson have developed the first radionuclide sensors for water monitoring that address these challenging requirements.

This final report is based on two joint EMSP projects conducted by the Pacific Northwest National Laboratory and Clemson University. In total, these projecte spanned six years. The sections below summarize some of the outcomes of this collaborative research effort.

\section{FUNDING}

Radionuclide Sensors for Water Monitoring, proposal and renewal, 6 years total. This work could not be renewed after FY05 due to the changed focus of the EMSP vadose zone program.

PNNL: $\quad$ FY00, 01, 02, \$200K per year

FY03, 04, 05 \$206K per year

Clemson: $\quad$ FY00, 01, 02, \$75K per year FY03, 04, $05 \$ 80 \mathrm{~K}$ per year

Radioanalytical Chemistry for Automated Nuclear Waste Process Monitoring, proposal and renewal. This work was canceled beyond FY06 with the elimination of the EMSP high level waste program.

PNNL: $\quad$ FY02, 03, 04 \$233K per year

Clemson FY02, 03, 04 \$117K per year
FY05, 06 \$240K per year (2 yrs only)

FY05, 06 \$100K per year (2 yrs only) 


\section{PRODUCTIVITY}

\section{Publications}

1. Egorov, O.B., M.J. O'Hara, and J.W. Grate, Equilibration-Based Preconcentrating Minicolumn Sensors for Trace Level Monitoring of Radionuclides and Metal Ions in Water without Consumable Reagents. Anal. Chem., 2006. Accepted.

2. Hughes, L.D. and T.A. DeVol, Evaluation of flow cell detector configurations combining simultaneous preconcentration and scintillation detection for monitoring of pertechnetate in aqueous media. Anal.Chem., 2006. 78(7): p. 2254-2261.

3. Hughes, L.D. and T.A. DeVol, Characterization of a Teflon (R) coated semiconductor detector flow cell for monitoring of pertechnetate in groundwater. J. Radioanal. Nucl. Chem., 2006. 267(2): p. $287-$ 295.

4. Roane, J.E. and T.A. DeVol, Evaluation of an extractive scintillation medium for the detection of uranium in water. J. Radioanal. Nucl. Chem., 2005. 263(1): p. 51-57.

5. Hughes, L.D., B.A. Powell, A.M. Soreefan, D.A. Falta, and T.A. DeVol, Anomalously high levels of uranium and other naturally occurring radionuclides in private wells in the piedmont region of South Carolina. Health Physics, 2005. 88(3): p. 248-252.

6. Fjeld, R.A., T.A. DeVol, J.D. Leyba, and A. Paulenova, Measurement of radionuclides using ion chromatography and on-line radiation detection. Journal of Radioanalytical and Nuclear Chemistry, 2005. 263(3): p. 635-640.

7. Egorov, O.B., M.J. O'Hara, J.W. Grate, M. Knopf, G. Anderson, and J. Hartman, Radiochemical Sensor System for the Analysis of 99Tc(VII) in Groundwater. J. Radioanal. Nucl. Chem., 2005. 264: p. 495-500.

8. Egorov, O.B., R.S. Addleman, M.J. O'Hara, T. Marks, and J.W. Grate, Direct measurement of alpha emitters in liquids using passivated ion implanted planar silicon (PIPS) diode detectors. Nuclear Instruments \& Methods in Physics Research, Section A: Accelerators, Spectrometers, Detectors, and Associated Equipment, 2005. 537(3): p. 600-609.

9. Egorov, O., M.J. O'Hara, and J.W. Grate, Automated Radiochemical Analysis of Total Tc-99 in Aged Nuclear Waste Processing Streams. J. Radioanal. Nucl. Chem., 2005. 263: p. 629-633.

10. Addleman, R.S., M.J. O'Hara, T. Marks, J.W. Grate, and O.B. Egorov, Direct actinide assay with surface passivated silicon diodes. J. Radioanal. Nucl. Chem., 2005. 263(2): p. 295-300.

11. Addleman, R.S., M.J. O'Hara, J.W. Grate, and O.B. Egorov, Chemically enhanced alpha-energy spectroscopy in liquids. J. Radioanal. Nucl. Chem., 2005. 263(2): p. 291-294.

12. Addleman, R.S., O.B. Egorov, M.J. O'Hara, B. Busche, T.S. Zemanian, and G. Fryxell, Preconcentration and assay of radionuclides with self assembled monolayers on mesoporous supports. Journal of Radioanalytical and Nuclear Chemistry, 2005. 263(1): p. 59-64.

13. Grate, J.W., O.B. Egorov, and M.J. O'Hara, Sensors and Automated Analyzers for Radionuclides. ACS Symposium Series, 2004. 904(Subsurface Contamination Remediation): p. 322-341.

14. Fjeld, R.A., J.E. Roane, J.D. Leyba, A. Paulenova, and T.A. DeVol, Sequential and simultaneous radionuclide separation-measurement with flow-cell radiation detection, in Radioanalytical Methods in Interdisciplinary Research. 2004. p. 105-119.

15. Egorov, O.B., M.J. O'Hara, and J.W. Grate, Microwave-Assisted Sample Treatment in a Fully Automated Flow-Based Instrument: Oxidation of Reduced Technetium Species in the Analysis of Total Technetium-99 in Caustic Aged Nuclear Waste Samples. Anal. Chem., 2004. 76: p. 3869-3877.

16. Egorov, O.B., M.J. O'Hara, R.S. Addleman, and J.W. Grate, Automation of radiochemical analysis: From groundwater monitoring to nuclear waste analysis. ACS Symposium Series, 2004. 868(Radioanalytical Methods in Interdisciplinary Research): p. 246-270.

17. Ayaz, B. and T.A. DeVol, Experimental-theoretical response of a $\mathrm{ZnS}(\mathrm{Ag}$ ) scintillating disc for gross-alpha measurements of aqueous radioactivity. Ieee Transactions on Nuclear Science, 2004. 51(4): p. 1688-1692. 
18. Theisen, C.D., T.A. DeVol, and D.P. DiPrete, Quantification of quench on alpha/beta pulse shape discrimination of liquid scintillation cocktails. Health Physics, 2003. 84(6): p. S167-S168.

19. Tan, H. and T.A. DeVol, Monte Carlo modeling of heterogeneous scintillation flow-cell detectors. Nuclear Instruments \& Methods in Physics Research Section a-Accelerators Spectrometers Detectors and Associated Equipment, 2003. 515(3): p. 624-633.

20. Roane, J.E., T.A. DeVol, J.D. Leyba, and R.A. Fjeld, The use of extraction chromatography resins to concentrate actinides and strontium from soil for radiochromatographic analyses. Journal of Environmental Radioactivity, 2003. 66(3): p. 227-245.

21. Hughes, L. and T.A. DeVol, On-line gross alpha radiation monitoring of natural waters with extractive scintillating resins. Nuclear Instruments \& Methods in Physics Research Section aAccelerators Spectrometers Detectors and Associated Equipment, 2003. 505(1-2): p. 435-438.

22. Grate, J.W. and O.B. Egorov, Automated Radiochemical Separation, Analysis, and Sensing, in Handbook of Radioactivity Analysis (2nd Ed.). 2003, Elsevier. p. 1129-1164.

23. Ayaz, B. and T.A. DeVol, Application of $\mathrm{MnO} 2$ coated scintillating and extractive scintillating resins to screening for radioactivity in groundwater. Nuclear Instruments \& Methods in Physics Research Section a-Accelerators Spectrometers Detectors and Associated Equipment, 2003. 505(1-2): p. 458461.

24. Tan, H. and T.A. DeVol, Development of a flow-cell alpha detector utilizing microencapsulated CsI : Tl granules and silicon PIN-photodiodes. Ieee Transactions on Nuclear Science, 2002. 49(3): p. 12431248.

25. Roane, J.E. and T.A. DeVol, Simultaneous Separation and Detection of Actinides in Acidic Solutions Using an Extractive Scintillating Resin. Anal. Chem., 2002. 74(21): p. 5629-5634.

26. Egorov, O., M.J. O'Hara, and J.W. Grate. Radionuclide selective sensors for water monitoring: 99Tc(VII) detection in Hanford groundwater. in Spectrum 2002:. 2002. Reno, NV: American Nuclear Society, La Grange Park, Ill.

27. DeVol, T.A., A.H. Ringberg, and R.A. Dewberry, Isotopic analysis of plutonium using a combination of alpha and internal conversion electron spectroscopy. Journal of Radioanalytical and Nuclear Chemistry, 2002. 254(1): p. 71-79.

28. Fjeld, R.A., T.A. DeVol, R.W. Goff, M.D. Blevins, D.D. Brown, S.M. Ince, and A.W. Elzerman, Characterization of the mobilities of selected actinides and fission/activation products in laboratory columns containing subsurface material from the Snake River Plain. Nuclear Technology, 2001. 135(2): p. 92-108.

29. Egorov, O.B., M.J. O'Hara, O.T. Farmer, III, and J.W. Grate, Extraction chromatographic separations and analysis of actinides using sequential injection techniques with on-line inductively coupled plasma mass spectrometry (ICP MS) detection. Analyst, 2001. 126(9): p. 1594-1601.

30. DeVol, T.A., O.B. Egorov, J.E. Roane, A. Paulenova, and J.W. Grate, Extractive scintillating resin for 99Tc quantification in aqueous solutions. J. Radioanal. Nucl. Chem., 2001. 249(1): p. 181-189.

31. DeVol, T.A., J.M. Duffey, and A. Paulenova, Combined extraction chromatography and scintillation detection for off-line and on-line monitoring of strontium in aqueous solutions. J. Radioanal. Nucl. Chem., 2001. 249(2): p. 295-301.

32. Coates, J.T., R.A. Fjeld, A. Paulenova, and T. DeVol, Evaluation of a rapid technique for measuring actinide oxidation states in a ground water simulant. Journal of Radioanalytical and Nuclear Chemistry, 2001. 248(2): p. 501-506.

33. Tan, H., T.A. DeVol, and R.A. Fjeld, Digital alpha/beta pulse shape discrimination of CsI : Tl for online measurement of aqueous radioactivity. Ieee Transactions on Nuclear Science, 2000. 47(4): p. 1516-1521.

34. DeVol, T.A., J.E. Roane, J.M. Williamson, J.M. Duffey, and J.T. Harvey, Development of scintillating extraction media for separation and measurement of charged-particle-emitting radionuclides in aqueous solutions. Radioact. Radiochem., 2000. 11(1): p. 34-46. 


\section{Doctorate Theses}

Roane, J.E., (Ph.D.), "Radionuclide Separation using Coupled Chromatographic and Scintillation Detection Techniques", (August, 2001).

Tan, H., (Ph.D.), "Measurement of Radioactivity in Aqueous Solutions by Heterogeneous Scintillation Detection with Comparison to Stochastic Models", (May 2002).

Hughes, L.D. (Ph.D.), "Radionuclide Sensors for Monitoring of ${ }^{99} \mathrm{TcO}_{4}{ }^{-}$in Aqueous Solutions: Characterization of Detector Configurations and Data Analysis Methods", (May 2006).

\section{Masters Theses}

Drumm, L., (M.S.) "Gross Alpha-Radiation Monitoring of Natural Waters," (May 2002).

Chandrikamohan, P. (M.S.) "Comparison of Pulse Shape Discrimination Methods for BC400/BGO Phoswich and CsI:Tl Detectors," December 2004.

Soreefan, A. (M.S.) "Experimental and Monte Carlo Investigation of the Light Collection Efficiency of Heterogeneous Scintillation Flow Cell Detectors," non-thesis option August 2003.

Lolap, G. (M.S.) " CsI:T1 Temporal Luminosity Dependence on Radiation type and Energy", May 2006. 


\section{TECHNICAL PROGRESS}

This section only serves to highlight selected progress from work in our EMSP project, "Radionuclide Sensors for Water Monitoring", that are of particular relevance to a addressing the need within DOE. This work has resulted in numerous publications which provide more details.[135] PNNL and Clemson have both developed a number of sensing approaches for various radionuclides using scintillating methods $[2,4,7,14,21,23,25,30,31,34-36]$ and diodes $[1,8,10,11]$. The scintillation-based sensors are described below. Treatment of diode-based sensors will be limited in this Narrative. In parallel, Clemson has advanced the state of the art in radiometric detection, flow cell design, and digital signal processing.

\section{Radionuclide Sensors based on Combined Separation and Scintillation Approaches (PNNL and Clemson)}

If the radionuclides captured on an analytical separation column could be detected in place, the column would become a sensor. We have successfully demonstrated this approach by combining scintillating materials with separation materials, typically as preconcentrating minicolumn sensors.[2-4,7,13,14,16,21$23,25,26,30,31,34,35]$ These columns perform both selective capture of radionuclides and transduction of the presence of captured radionuclides into a measurable signal. The latter function is achieved by either incorporating scintillating fluors into chemically selective beads (dual functionality beads), or as a mixture of scintillating particles with chemically selective beads (composite beds). Light output is measured using photomultiplier tubes (PMTs). The preconcentrating minicolumn sensor concept is shown in Figure 1.
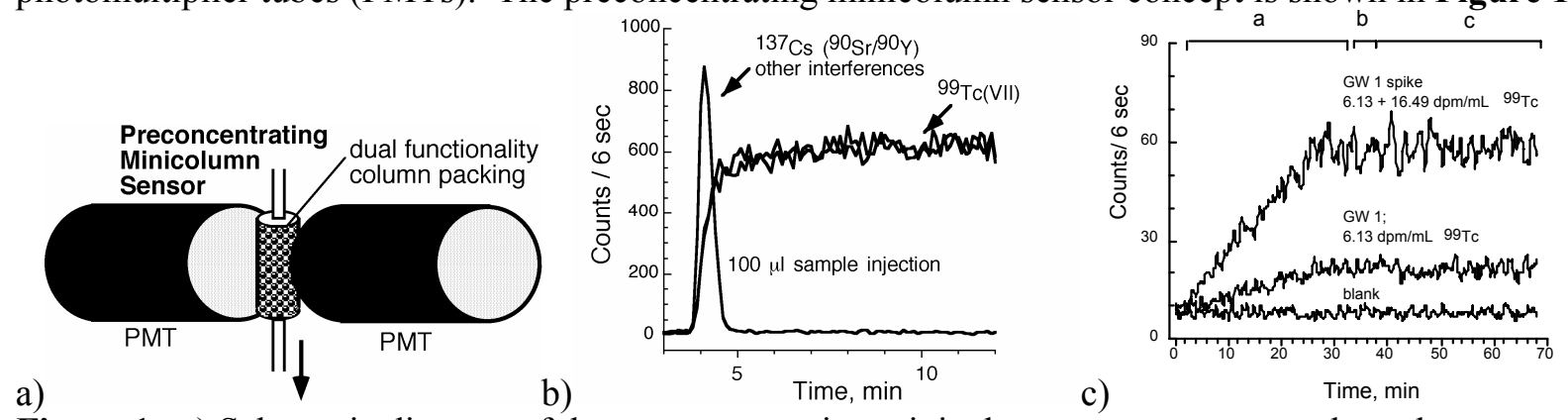

Figure 1. a) Schematic diagram of the preconcentrating minicolumn sensor concept where the transparent column body is placed between two PMTs for light collection. The packing material in the column body contains both selective separation chemistry and scintillating materials to generate a luminescent output. b) Sensor response to injected aliquots of ${ }^{99} \mathrm{Tc}(\mathrm{VII})$ analyte and potentially interfering species $\left({ }^{137} \mathrm{Cs}\right)$ unretained by the sensor material, which contained Aliquat 336 and scintillating fluors. c) Calibration traces showing uptake and stopped flow counting in the quantitative capture analytical approach.

The chemically selective materials are typically extraction chromatographic resins, solid phase extraction particles, or ion exchange resins. If so desired, renewable separation column techniques can be used to deliver or renew the sensing material or mixture. [35,37-41] Planar and coiled tubing geometries containing composite beds or dual functionality beads have also been examined, as well as planar geometries with dual functionality cast membranes. The ability to design sensors in either column or planar formats provides greater versatility in the development of sensors for field applications.

This sensing concept is designed to meet the challenging requirements for the sensing of $\alpha$ - and $\beta$ emitting radionuclides in water. These radionuclides emit particles with short penetration ranges in condensed media and must be detected to ultra-trace analytical detection limits. The close proximity of selective chemistries and scintillating materials in particles of the order of 10-250 microns in diameter enables 
radiometric detection of $\alpha$ or $\beta$ emissions from the captured radionuclides. Because of the relatively long range of the $\beta$ particles, this approach appears to be particularly suitable for detection of $\beta$-emitters such as ${ }^{99} \mathrm{Tc}$ and ${ }^{90} \mathrm{Sr}$. The ranges in water for $\beta$ particles emitted by ${ }^{90} \mathrm{Y}\left(\mathrm{E}_{\max }=2282 \mathrm{keV}\right),{ }^{90} \mathrm{Sr}\left(\mathrm{E}_{\max }=546 \mathrm{keV}\right)$, and ${ }^{99} \mathrm{Tc}\left(\mathrm{E}_{\max }=294 \mathrm{keV}\right)$ are $1.1 \mathrm{~cm}, 1.8 \mathrm{~mm}$, and $750 \mu \mathrm{m}$ respectively. However, it can be used for actinides as well, albeit with less detection efficiency. The range of a $5.5 \mathrm{MeV} \alpha$ particle emitted by ${ }^{241} \mathrm{Am}$ is about 47 $\mu \mathrm{m}$ in water.

This configuration meets all the functional requirements for these sensors. The packed column format provides for efficient fluidic processing of the sample for preconcentration. The detection method is radiometric via the process of scintillation. Selective chemistry is in very close proximity to the scintillation material and retains the radionuclides for counting. These new preconcentrating minicolumn sensors represent a novel and advantageous approach for detection of radionuclides when selective preconcentration is required. For the analysis of important radionuclide contaminants such as ${ }^{99} \mathrm{Tc}$ radiometric detection offers much lower detection limits than those possible by chemical sensing approaches. Figure 1b illustrates the capture and retention of ${ }^{99} \mathrm{Tc}$ by such a sensor, while unretained radionuclides produce only a transient signal. Signals from ${ }^{99} \mathrm{Tc}$-contaminated groundwater analyses are showin in Figure 1c.

PNNL and Clemson have demonstrated radionuclide sensors for ${ }^{99} \mathrm{Tc}$ and ${ }^{90} \mathrm{Sr}$, as well as actinides and uranium, using the dual functionality bead and composite bed approaches. Accurate detection in chemically untreated Hanford groundwater samples was demonstrated for ${ }^{99}$ Tc, and it could be detected to below drinking water standard limits. Captured pertechnetate can be released from the column using carbonate solutions, an environmentally benign reagent, since carbonate is already present in the subsurface. Portable detectors were demonstrated in some cases.

Using composite bed columns, solid phase extraction materials that cannot easily be made into dual functionality beads could be used for radionuclide sensors, broadening the range of potential separation materials. These materials are also more stable than dual functionality beads based on extraction chromatographic resins, which can leach the extractants over long periods of time, and where the fluor molecules are unstable to some solution conditions.

The idea of combining scintillating properties with chemical interactions in microspheres, as we describe, is not entirely new, but it had not been applied to radionuclide sensor designs before our efforts. Preparation of polymeric ion exchange beads with scintillating properties was reported 30 years ago, but the collection of radionuclides from the sample and subsequent counting were performed manually in separate steps. [42] This work resulted in practically no follow-up work relevant to radiochemical analysis.[43] To the best of our knowledge, the results from PNNL and Clemson University represent some of the first chemically selective scintillating sensors for radiochemical analysis applications. Moreover, these sensors have now been demonstrated for radionuclide uptake from chemically untreated groundwater matrixes, and for detection to ultra-trace levels necessary to meet regulatory limits.

With parallel funding from the DOE-EM Advanced Monitoring Systems Initiative, PNNL has developed engineered prototypes of the preconcentrating minicolumn sensor in form factors designed for down-well applications. Some images are shown in Figure 2. Second generation prototypes in a smaller simpler configuration are now being developed. However, it should be noted that these prototypes represent the hardware component. The sensing functionality is critically dependent on the separation chemistry installed, the method of combining scintillation and separation, and the analytical approach. These features are the ones we have been developing under the EMSP funding and which we hope to continue developing in the ERSP program. This prototype hardware was designed to implement an analytical approach we call equilibration-based sensing, which is further described below. 
a)

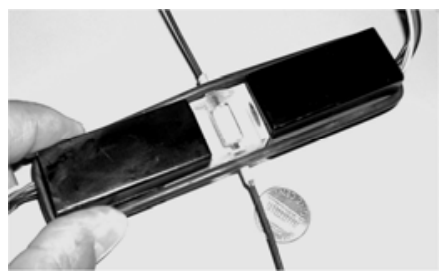

b)

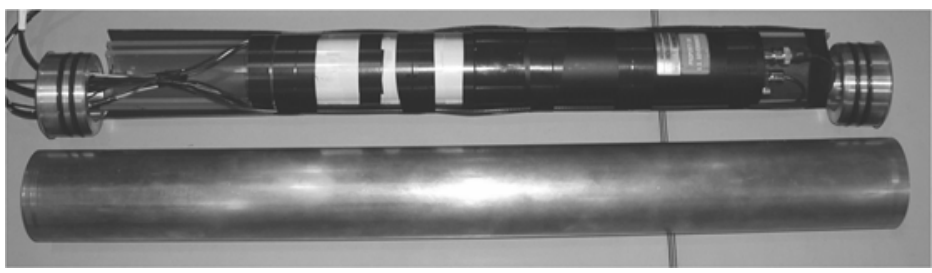

Figure 2. a) The sensor flow cell between two PMTs. b) Complete probe unit.

\section{Equilibration-based Radionuclide Sensing (PNNL)}

The preconcentrating minicolumn sensor was originally developed for quantitative capture of radionuclides on the column, without breakthrough, and required reagents to regenerate the column. While this approach represented a milestone in the development of radionuclide sensors for water monitoring, and succeeded at meeting stringent detection limit requirements, the use of reagents to regenerate the sensor column for each and every measurement is a potential drawback for in situ monitoring applications. We have recently developed a new analytical approach for the preconcentrating minicolumn sensors that we call "equilibration-based" sensing. (More details can be found in our accepted manuscript in the Appendices.) The equilibration-based approach sets out to deliberately achieve full breakthrough conditions where the analyte concentration exiting the column is the same as the analyte concentration entering the column. Under these conditions, the sensing material in the column has equilibrated with the analyte concentration in solution, and the extent of preconcentration is maximized. Under trace detection conditions, i.e. on the low concentration, linear portion of the sorption isotherm, the amount captured on the column material is proportional to the analyte concentration. Because capture is based on dynamic equilibrium, it is also reversible. On re-equilibration to another sample or blank, the signal will go up or down accordingly. In principle, no consumable reagents are required in this equilibration-based analytical approach.

Although delivery of sufficient sample through the sensor to achieve equilibration can be time consuming, speed of response is not typically a requirement for an in situ sensor for long-term monitoring. Changes occurs slowly in the subsurface and monitoring intervals are long. A sensor could be equilibrated, the signal determined, and then sealed using valves until the next measurement. Then a new sample would be introduced and equilibrated to get another measurement. A reversible equilibration-based sensor requiring no reagents could work in the field for tens of measurements or years of use.

This approach has been investigated in detail for ${ }^{99}$ Tc sensing (as pertechnetate), which can be easily sensed to levels 10-fold lower than the required detection limits in chemically untreated Hanford site groundwater. We have also demonstrated proof of principle for ${ }^{90} \mathrm{Sr}$ sensing. The method can also be used to detect hexavalent chromium, a metal contaminant of interest, using spectroscopic rather than radiometric detection. Further details are in our manuscript in the appendices.
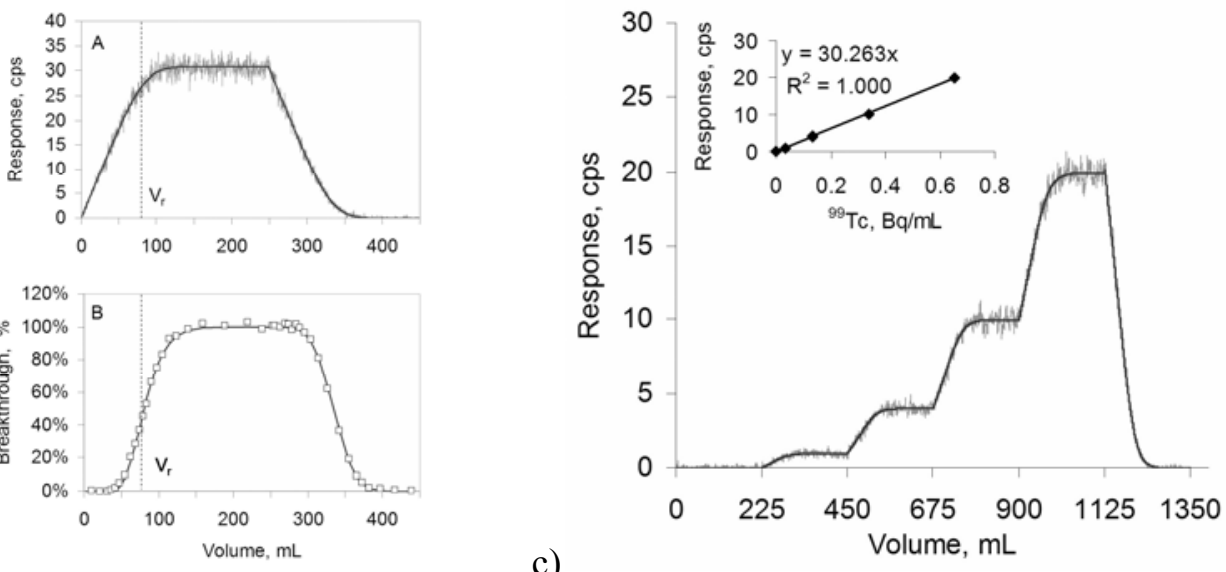

$\mathrm{a}, \mathrm{b})$

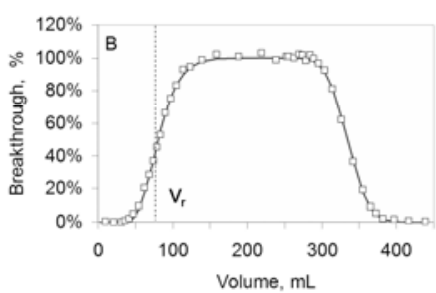

c)

Figure 3. Responses of the pertechnetate composite bed sensor to standards in $0.01 \mathrm{M}$ nitric acid. 
Equilibration-based sensing is illustrated in Figure 3, which shows sensor responses to pertechnetate standards, where the lowest standard in $\mathbf{3 c}$ is at the drinking water limit, and is easily observable above the noise. This sensor column contains a composite bed of AG 4-X4 weakly basic anion exchange resin and Bicron BC-400 scintillating beads in a 1:4 dry weight ratio. Because the range of the ${ }^{99} \mathrm{Tc} \beta$-particles $(\sim 750$ $\mu \mathrm{m}$ in water) is greater than the diameter of the sorbent bead (typically $<150 \mu \mathrm{m}$ ), adequate scintillation detection efficiency was anticipated in this configuration; the absolute detection efficiency of the retained analyte was $38 \pm 1 \%$. The AG 4-X4 anion exchange bead material, with dimethylaminomethyl functionality covalently attached to acrylic beads, has good affinity and selectivity for uptake of pertechnetate from low acid to slightly basic solutions. Use of anion exchange materials for pertechnetate separations is well known.[35,44-51] Figure 3a,b illustrate the sensor response and \% breakthrough for a single Tc standard followed by a blank. A steady state signal is observed at full breakthrough, and the response is completely reversible. Figure 3c shows step responses to multiple standards, and a linear calibration curve in the inset. Although these experiments were done in weak acid, we have subsequently shown similar results in chemically untreated Hanford groundwater.

We examined several ratios of scintillator beads to ion exchange beads (w/w ratios of 1.5, 4, 9 and 14 ) for their effects on pertechnetate retention volume $V_{r}$, detection efficiency, $E_{d}$, and measurement efficiency $E_{m}=V_{r} E_{d}$. (This measurement efficiency is also the sensitivity for an equilibration-based sensor.) For ${ }^{99} \mathrm{Tc}$ spiked into pristine Hanford groundwater, the smallest ratio gives the largest retention volume and the smallest detection efficiency, as one might expect. More sorbent retains more analyte, and less scintillator results in less signal. The measurement efficiency was best at the lowest ratio; in addition, the Figure of Merit, (FOM) defined as measurement efficiency squared divided by the background count rate, was also best at the lowest tested ratio. On this basis, in pristine groundwater, the 1.5 ratio is preferred. For Tc standards from 0.033 to $0.73 \mathrm{~Bq} / \mathrm{mL}$, where $0.033 \mathrm{~Bq} / \mathrm{mL}$ is the drinking water standard, 50 minutes of pumping a 2 $\mathrm{mL} / \mathrm{min}$ was sufficient to equilibrate the column (at this 1.5 ratio). Counting for 70 minutes provided sufficient precision that 10x lower levels than the drinking water standard should be detectable, for a total measurement time of 120 minutes.

\section{Equilibration-based Sensing Theory (PNNL)}

It can be readily shown that the radiometric count rate, $R_{c / s, e q}$, in counts/second (c/s) of a sensor column that is fully equilibrated with a sample containing an analyte activity, $A_{a}$, expressed in $\mathrm{Bq} / \mathrm{mL}$, is $R_{c / s, e q}=E_{d} A_{a} V_{r}$, where $V_{r}$ is the retention volume (i.e., the volume of sample that contains the same quantity of analyte as the quantity of analyte captured by the sensor column at equilibration). The time- or volumedependent response of the sensor can also be modeled, although the derivation is not so simple, using theory derived from frontal chromatography.[52-54] We have developed this theory for the equilibration-based sensor and it is present in the manuscript in the Appendices.

Equilibration-based sensing theory is based on the fact the analyte ions enter and exit the column with a distribution of individual velocities through the column (or equivalently a distribution of volumes that eluted them.) Their velocities vary due to random diffusion, randomness in the length of time each is captured on the stationary phase, and random travel around the column packing. In conventional chromatography with a single injection, this distribution leads to a peak with a typically normal Gaussian shape. In frontal chromatography, a step change in concentration at the input results in a sigmoidal profile in the output as seen in Figure 3B, which is the integral of a normal distribution. The theory will not be presented in detail here; it is in a paper in the Appendices. [3] It models the effluent concentration as a function of volume resulting from a step change in concentration at the input. It further models the amount of the analyte that has passed through the sensor column after delivering a given sample volume, as well as the amount of analyte present on the sensor column after delivery of a given sample volume. Finally the sensor count rate in counts/second (c/s) as a function of sample volume is determined. For columns with low plate numbers, as may be the case with the radionuclide sensors, we described a Low Plate Model (LPM) based on breakthrough profile equations proposed by Lovkist. [55,56] 
The plots in Figure 3 show actual data as traces or data points. The model fits to the data are solid lines, and clearly provide a very accurate fit. The fits to the models enable one to use experimental response or breakthrough data to determine values for the column theoretical plates, $N$, the retention volume, $V_{r}$, and the detection efficiency, $E_{d}$. The validity of these values from the model fits were confirmed by comparing these values with independent values of $N$, determined from the breakthrough curve, $E_{d}$, determined independently, and the product of $V_{r} E_{d}$, determined from the slope of the calibration curve. Thus, the new theory provides an accurate description of sensor behavior, and enables detailed characterization in terms of chromatographic parameters. This characterization is useful when evaluating sensor behavior while varying parameters in sensor construction or in response to different matrix conditions. We also found that low plate number columns (e.g. down to 2 or 3 ) could make effective sensors.

By exercising these models, we can elucidate features of the chromatographic equilibration-based sensing that are useful in understanding behavior and designing sensors. In general, the lower the column theoretical plates, the less distinct the transition from linear uptake to steady state equilibrium as shown in Figure 4a, and the larger the volume needed to achieve full equilibration $\left(\mathrm{V}_{\mathrm{eq}}\right)$ relative to the retention volume (Figure 4b).

a)

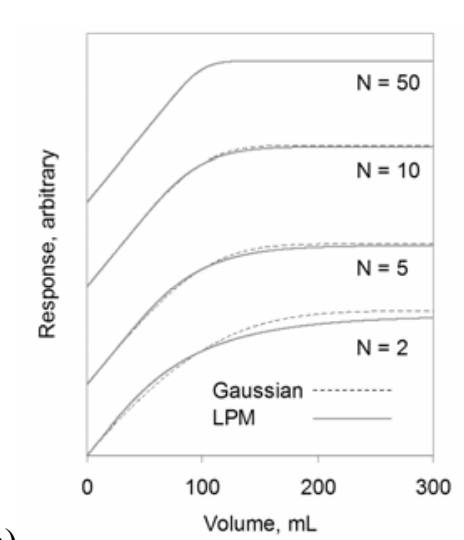

Figure 4. a) Predicted responses for systems with increasing number of theoretical plates $(N)$. b) Ratio of the breakthrough volume at $99 \%$ response to the retention volume as a function of plate numbers.

However, the manner in which one changes the theoretical plates is important in understanding the practical consequences of these observations. The theoretical plates of a radionuclide sensor can be changed by changing the length for the same diameter and material packing, by changing the ratio of sorbent to scintillator beads, and by changing the sorbent material. Further exercising the models, we examined the case where the length of a column was varied to increase the theoretical plates and retention volume, while keeping the diameter and column packing material constant. This analysis revealed that the volume in excess of the retention volume $\left(V_{\mathrm{eq}}-V_{r}\right)$, that is needed to equilibrate the column, does not vary much. For low plate number columns where $V_{\text {eq }}$ and $\left(V_{\text {eq }}-V_{r}\right)$ are much greater than $V_{r}$, increasing length is worthwhile, doubling the amount of analyte captured (and hence doubling sensitivity) with a small penalty in terms of additional volume that must be pumped. On the other hand if the column has a large plate number to begin with, where $V_{e q}-V_{r}$ is much less than $V_{r}$, doubling the length nearly doubles the volume necessary to equilibrate. Thus, these models allow one to rationally consider how various design changes such as column length will affect important sensor parameters such as the sensitivity and the volume of sample required for equilibration. We have only just begun to explore how this theory can be applied to characterize and direct the design of radionuclide sensors.

\section{Radiometric Detection Flow Cells, Modeling, and Digital Signal Processing (Clemson)}

Radiometric detection and digital signal processing are an integral part of the overall scheme for the quantification of radioactivity in solution. The flow-cell detector design is critical to the optimum detection 
of the analyte of interest. In cases where the chemical separation is not ideal, the radiometric detector can be designed such that it will preferentially detect the radionuclide of interest. Using techniques developed under the previous EMSP, we have demonstrated the trade-offs of optimized detector geometry and the advantages of digital signal processing. We have shown that digital pulse processing and digital pulse shape discrimination can be utilized to enhance the signal to noise. The brief highlights of some of these previous findings are presented below.

Planar flow-cell detectors based on a fountain cell design[57] were developed for simultaneous concentration and scintillation detection of ${ }^{99} \mathrm{Tc}$ in water. (See the publication in the Appendices for more detail.) The fountain flow-cell design, shown in Figure 5, is based on radial solution flow from the center of the planar resin bed to the periphery, interfaced with a photomultiplier tube. It will concentrate most of the initially retained activity in the center, where the PMT has the highest sensitivity. The sorptive scintillating media investigated were 1) an extractive scintillator (dual functionality beads) combining a porous polystyrene resin with the extractant Aliquat-336 and fluor 2-(1-naphtyl)-5-phenyloxazole - TcES, 2) a composite bed of organic scintillator (BC-400) and Tc-selective resin (TEVA ${ }^{\circledR}$ ) and 3) a composite bed of inorganic scintillator particles $\left(\mathrm{CaF}_{2}: \mathrm{Eu}\right)$ with either TEVA ${ }^{\circledR}$ resin or strong base anion exchange resin (Dowex ${ }^{\circledR} 1 \times 8-400(\mathrm{Cl})$ ). Technetium-99 detection efficiencies for the fountain flow-cell ranged from $10.33 \%$ for the TcES resin to $50.20 \%$ for the $\mathrm{CaF}_{2}: \mathrm{Eu} /$ Dowex $^{\circledR}$. The loading efficiencies were all above $98 \%$. The background count rates ranged from $1.57 \mathrm{cps}$ for the $\mathrm{BC}-400 / \mathrm{TEVA}^{\circledR}$ to $9.88 \mathrm{cps}$ for the $\mathrm{CaF}_{2}: \mathrm{Eu} / \mathrm{Dowex}{ }^{\circledR}$. The lowest MDA was predicted to be $2.97 \mathrm{~Bq}$ for the $\mathrm{CaF}_{2}: \mathrm{Eu} /$ Dowex ${ }^{\circledR}$ flow-cell. When preconcentrating $200 \mathrm{~mL}$ of solution, the lowest predicted MDC is $15.09 \mathrm{~Bq} \mathrm{~L}^{-1}$, which is significantly below the $33 \mathrm{~Bq} \mathrm{~L}^{-1}$ drinking water level.
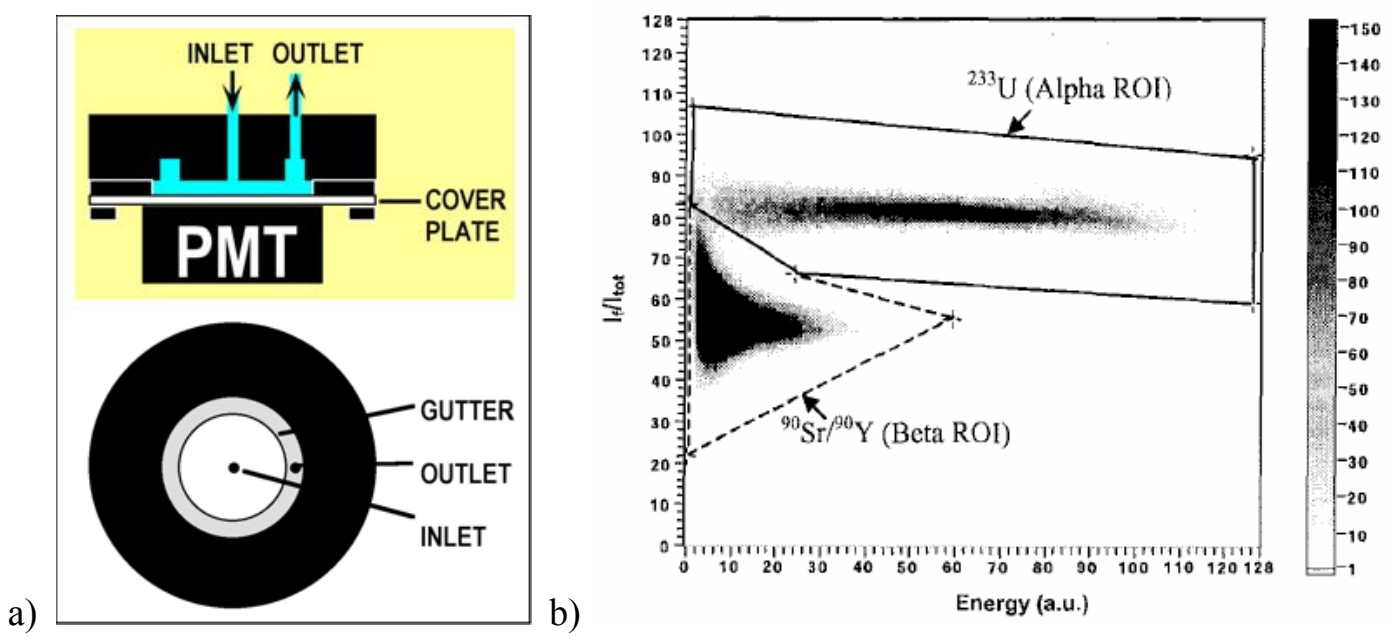

Figure 5. a) Schematic diagram of a fountain cell flow cell design for radiometric sensing. b) Schematic diagram of pulse shape discrimination between alpha and beta radiation.

An alternative flow-cell detection system used a Teflon ${ }^{\circledR}$-coated passivated ion-implanted planar silicon semiconductor diode detector for radiometric detection instead of scintillation. The detector was coupled to a $20-\mathrm{mL}$ flow-cell and $0.01 \mathrm{~g}$ of a strong base anion exchange resin (Dowex ${ }^{\circledR} 1 \times 8-400\left(\mathrm{Cl}^{-}\right), 3.5$ $\mathrm{meq} / \mathrm{g}$ capacity) was suspended in the aqueous solution contained in the flow-cell. The flow mode detection efficiency for ${ }^{99} \mathrm{Tc}$ was determined to be $17.66 \%$. The very low detector background resulted in a minimum detectable activity of only $0.38 \mathrm{~Bq}$, so that only a very small preconcentration volume is required for detection at the regulatory level.

Thus, planar flow cell designs have been demonstrated for both scintillation and semiconductor diode based radiation detection. Planar configurations offer flexibility in the geometry of the selective materials and transducing materials, as well as creating opportunities for placing permeable membranes between the groundwater and the separation/tranduction materials (to prevent some forms of fouling). 
Numercial modeling efforts have been approached from primarily two directions: charged particle interactions and fundamental pulse shape discrimination capability determination. Heterogeneous flow-cell detectors packed with scintillator granules were simulated with the Monte Carlo code, PENELOPE (Version 2000), for the detection of beta particles in aqueous media. (See publication in the Appendices for more detail.) The simulations were run for monoenergetic electrons at the average and endpoint energies of common beta-emitting radionuclides. PENELOPE was used to simulate the electron interactions as a means of investigating the effects of: packing geometry of scintillator granules, scintillator granule size, and the energy and initial location of electrons within the flow-cell on the fraction of energy deposited in the scintillator and the geometrical detection efficiency. Packing geometry (porosity) and scintillator material have strong effects at all electron energies. Initial electron energy and location of radioactivity only have strong effects at low electron energies. Scintillator sphere diameter has a greater effect on energy deposition at low electron energy than at high energy. The results of these findings are important in the optimization of a flow-cell for a particular radionuclide. For low energy (approximately less than $180 \mathrm{keV}$ ) radionuclides, the scintillator should have low density to reduce backscattering, and small granule size $(<100 \mu \mathrm{m})$. For medium energy (approximately between 180 and $550 \mathrm{keV}$ ) radionuclides, the scintillator should have high density to reduce energy lost in the aqueous phase, and medium granule size $(\sim 100 \mu \mathrm{m})$. For both low and medium energy radionuclides, the radionuclides are preferred to be absorbed into the scintillator or on its surface. For high energy (approximately above $550 \mathrm{keV}$ ) radionuclides, a higher density scintillator is preferred, while the granule size and radionuclide distribution are not critical. For all energy radionuclides, higher packing density is preferred.

Scintillators respond to energy deposition from ionizing radiation by emission of visible photons. Some scintillators have the physical property which yields dual decay mode temporal light pulses with varying characteristics of luminosities $A_{f}, A_{s}$, (fast and slow initial luminosities, respectively) and pulse decay times $\tau_{\mathrm{f}}, \tau_{\mathrm{s}}$, (fast and slow decay time constants). For investigation of the properties of pulse shape discrimination, hypothetical $\mathrm{A}_{\mathrm{f}}, \mathrm{A}_{\mathrm{s}}, \tau_{\mathrm{f}}$, and $\tau_{\mathrm{s}}$ parameters were applied to create a dynamic model within a Monte Carlo simulation system, Crystal Ball ${ }^{\mathrm{TM}}$. These temporal luminosity parameters thus defining the pulse shape allow one to conduct pulse shape discrimination (PSD). Monte Carlo simulations were also used to investigate the correlation between temporal luminosity parameters and pulse shape discrimination (PSD). The PSD capability of a scintillator was measured using charge comparison (CC) and constant time discrimination (CTD) PSD techniques, followed by quantification of the histogrammed pulse data (pulse shape spectrum) with FoM and spillover. In addition to the above simulations, experimental CsI:Tl PSD capabilities were compared with simulated values and were in good agreement. These studies successful in providing a few of the essential guidelines required when selecting scintillators for the purpose of effective radiation separation (i.e., for distinguishing different types or energies of radiation from one another, as may be the case for mixtures of radioactive co-contaminants such as ${ }^{99} \mathrm{Tc}$ and ${ }^{129} \mathrm{I}$ in certain locations on the Hanford site.

Digital signal processing (DSP) and pulse shape discrimination (PSD) offers greater flexibility and versatility in the analysis of scintillation pulses. Pulse shape discrimination is important in the determination of the incident radiation type and/or in the reduction of background radiation. Comparison of different pulse shape discrimination (PSD) methods was performed under two different experimental conditions and the best PSD method was identified. Beta/gamma discrimination of ${ }^{90} \mathrm{Sr} /{ }^{90} \mathrm{Y}$ and ${ }^{137} \mathrm{Cs}$ was performed using a phoswich detector made of BC400 $(2.5 \mathrm{~cm}$ OD x $1.2 \mathrm{~cm})$ and BGO $(2.5 \mathrm{~cm}$ O.D. x $2.5 \mathrm{~cm}$ ) scintillators. Alpha/gamma discrimination of ${ }^{210} \mathrm{Po}$ and ${ }^{137} \mathrm{Cs}$ was performed using a CsI:Tl $(2.8 \times 1.4 \times 1.4$ $\mathrm{cm}^{3}$ ) scintillation crystal. The pulse waveforms were digitized with a DGF-4C (X-Ray Instrumentation Associates, XIA) and analyzed offline with IGOR Pro software (Wavemetrics, Inc.). The four pulse shape discrimination methods that were compared include: digital constant fraction discrimination, rise time discrimination, constant time discrimination (CTD), and charge comparison methods. Both the phoswich and CsI:Tl detector configurations were optimized for each pulse shape discrimination method using both the FoM and the spillover metric. For this detector and PSD method, the optimum integration window was determined to be $0-3.0 \mu$ s for the FoM metric, resulting in a FoM of 3.72, and 0-6.75 $\mu$ s by the spillover metric, resulting in a spillover of $0.25 \%$. The charge comparison method resulted in a Figure of Merit (FoM) 
of 3.3 (9.9\% spillover) and 3.7 (0.033\% spillover) for the phoswich and the CsI:T1 detectors, respectively. An example of pulse shape discrimination is shown in Figure 5b.

Clemson's expertise in flow cell design, modeling, digital signal processing, and pulse shape discrimination, as well as their contributions to the overall development of radionuclide sensors that combine separation and scintillation materials, greatly contributed to the successful development of sensitive and selective radionuclide sensors for subsurface monitoring.

\section{LITERATURE CITED}

1. Hughes, L.D., and T.A. DeVol, Characterization of a Teflon (R) coated semiconductor detector flow cell for monitoring of pertechnetate in groundwater, J. Radional. Nucl. Chem., 267, 287-295 (2006).

2. Hughes, L.D., and T.A. DeVol, Evaluation of flow cell detector configurations combining simultaneous preconcentration and scintillation detection for monitoring of pertechnetate in aqueous media, Analytical Chemistry, 78, 2254-2261 (2006).

3. Egorov, O.B., M.J. O'Hara, and J.W. Grate, Equilibration-Based Preconcentrating Minicolumn Sensors for Trace Level Monitoring of Radionuclides and Metal Ions in Water without Consumable Reagents, Anal. Chem., 78, Accepted. (2006).

4. Roane, J.E., and T.A. DeVol, Evaluation of an extractive scintillation medium for the detection of uranium in water, J. Radioanal. Nucl. Chem, 263, 51-57 (2005).

5. Hughes, L.D., B.A. Powell, A.M. Soreefan, D.A. Falta, and T.A. DeVol, Anomalously high levels of uranium and other naturally occurring radionuclides in private wells in the piedmont region of South Carolina, Health Physics, 88, 248-252 (2005).

6. Fjeld, R.A., T.A. DeVol, J.D. Leyba, and A. Paulenova, Measurement of radionuclides using ion chromatography and on-line radiation detection, J. Radional. Nucl. Chem., 263, 635-640 (2005).

7. Egorov, O.B., M.J. O'Hara, J.W. Grate, M. Knopf, G. Anderson, and J. Hartman, Radiochemical Sensor System for the Analysis of 99Tc(VII) in Groundwater, J. Radioanal. Nucl. Chem., 264, 495-500 (2005).

8. Egorov, O.B., R.S. Addleman, M.J. O'Hara, T. Marks, and J.W. Grate, Direct measurement of alpha emitters in liquids using passivated ion implanted planar silicon (PIPS) diode detectors, Nuclear Instruments \& Methods in Physics Research, Section A: Accelerators, Spectrometers, Detectors, and Associated Equipment, 537, 600-609 (2005).

9. Egorov, O., M.J. O'Hara, and J.W. Grate, Automated Radiochemical Analysis of Total Tc-99 in Aged Nuclear Waste Processing Streams, J. Radioanal. Nucl. Chem., 263, 629-633 (2005).

10. Addleman, R.S., M.J. O'Hara, T. Marks, J.W. Grate, and O.B. Egorov, Direct actinide assay with surface passivated silicon diodes, J. Radioanal. Nucl. Chem., 263, 295-300 (2005).

11. Addleman, R.S., M.J. O'Hara, J.W. Grate, and O.B. Egorov, Chemically enhanced alphaenergy spectroscopy in liquids, J. Radioanal. Nucl. Chem., 263, 291-294 (2005).

12. Addleman, R.S., O.B. Egorov, M.J. O'Hara, B. Busche, T.S. Zemanian, and G. Fryxell, Preconcentration and assay of radionuclides with self assembled monolayers on mesoporous supports, J. Radional. Nucl. Chem., 263, 59-64 (2005).

13. Grate, J.W., O.B. Egorov, and M.J. O'Hara, Sensors and Automated Analyzers for Radionuclides, ACS Symposium Series, 904, 322-341 (2004). 
14. Fjeld, R.A., J.E. Roane, J.D. Leyba, A. Paulenova, and T.A. DeVol, Sequential and simultaneous radionuclide separation-measurement with flow-cell radiation detection, in Radioanalytical Methods in Interdisciplinary Research. 2004. p. 105-119.

15. Egorov, O.B., M.J. O'Hara, and J.W. Grate, Microwave-Assisted Sample Treatment in a Fully Automated Flow-Based Instrument: Oxidation of Reduced Technetium Species in the Analysis of Total Technetium-99 in Caustic Aged Nuclear Waste Samples, Anal. Chem., 76, 3869-3877 (2004).

16. Egorov, O.B., M.J. O'Hara, R.S. Addleman, and J.W. Grate, Automation of radiochemical analysis: From groundwater monitoring to nuclear waste analysis, ACS Symposium Series, 868, 246-270 (2004).

17. Ayaz, B., and T.A. DeVol, Experimental-theoretical response of a $\mathrm{ZnS}(\mathrm{Ag})$ scintillating disc for gross-alpha measurements of aqueous radioactivity, Ieee Transactions on Nuclear Science, 51, 1688-1692 (2004).

18. Theisen, C.D., T.A. DeVol, and D.P. DiPrete, Quantification of quench on alpha/beta pulse shape discrimination of liquid scintillation cocktails, Health Physics, 84, S167-S168 (2003).

19. Tan, H., and T.A. DeVol, Monte Carlo modeling of heterogeneous scintillation flow-cell detectors, Nuclear Instruments \& Methods in Physics Research Section a-Accelerators Spectrometers Detectors and Associated Equipment, 515, 624-633 (2003).

20. Roane, J.E., T.A. DeVol, J.D. Leyba, and R.A. Fjeld, The use of extraction chromatography resins to concentrate actinides and strontium from soil for radiochromatographic analyses, Journal of Environmental Radioactivity, 66, 227-245 (2003).

21. Hughes, L., and T.A. DeVol, On-line gross alpha radiation monitoring of natural waters with extractive scintillating resins, Nuclear Instruments \& Methods in Physics Research Section aAccelerators Spectrometers Detectors and Associated Equipment, 505, 435-438 (2003).

22. Grate, J.W., and O.B. Egorov, Automated Radiochemical Separation, Analysis, and Sensing, in Handbook of Radioactivity Analysis (2nd Ed.). 2003, Elsevier. p. 1129-1164.

23. Ayaz, B., and T.A. DeVol, Application of $\mathrm{MnO} 2$ coated scintillating and extractive scintillating resins to screening for radioactivity in groundwater, Nuclear Instruments \& Methods in Physics Research Section a-Accelerators Spectrometers Detectors and Associated Equipment, 505, 458-461 (2003).

24. Tan, H., and T.A. DeVol, Development of a flow-cell alpha detector utilizing microencapsulated CsI : Tl granules and silicon PIN-photodiodes, Ieee Transactions on Nuclear Science, 49, 1243-1248 (2002).

25. Roane, J.E., and T.A. DeVol, Simultaneous Separation and Detection of Actinides in Acidic Solutions Using an Extractive Scintillating Resin, Anal. Chem., 74, 5629-5634 (2002).

26. Egorov, O., M.J. O'Hara, and J.W. Grate. Radionuclide selective sensors for water monitoring: 99Tc(VII) detection in Hanford groundwater. in Spectrum 2002:. 2002. Reno, NV: American Nuclear Society, La Grange Park, Ill.

27. DeVol, T.A., A.H. Ringberg, and R.A. Dewberry, Isotopic analysis of plutonium using a combination of alpha and internal conversion electron spectroscopy, J. Radional. Nucl. Chem., 254, 71-79 (2002).

28. Fjeld, R.A., T.A. DeVol, R.W. Goff, M.D. Blevins, D.D. Brown, S.M. Ince, and A.W. Elzerman, Characterization of the mobilities of selected actinides and fission/activation products in laboratory columns containing subsurface material from the Snake River Plain, Nuclear Technology, 135, 92-108 (2001). 
29. Egorov, O.B., M.J. O'Hara, O.T. Farmer, III, and J.W. Grate, Extraction chromatographic separations and analysis of actinides using sequential injection techniques with on-line inductively coupled plasma mass spectrometry (ICP MS) detection, Analyst, 126, 1594-1601 (2001).

30. DeVol, T.A., O.B. Egorov, J.E. Roane, A. Paulenova, and J.W. Grate, Extractive scintillating resin for 99Tc quantification in aqueous solutions, J. Radioanal. Nucl. Chem., 249, 181-189 (2001).

31. DeVol, T.A., J.M. Duffey, and A. Paulenova, Combined extraction chromatography and scintillation detection for off-line and on-line monitoring of strontium in aqueous solutions, J. Radioanal. Nucl. Chem., 249, 295-301 (2001).

32. Coates, J.T., R.A. Fjeld, A. Paulenova, and T. DeVol, Evaluation of a rapid technique for measuring actinide oxidation states in a ground water simulant, J. Radioanal. Nucl. Chem, 248, 501-506 (2001).

33. Tan, H., T.A. DeVol, and R.A. Fjeld, Digital alpha/beta pulse shape discrimination of CsI : $\mathrm{Tl}$ for on-line measurement of aqueous radioactivity, Ieee Transactions on Nuclear Science, 47, 1516-1521 (2000).

34. DeVol, T.A., J.E. Roane, J.M. Williamson, J.M. Duffey, and J.T. Harvey, Development of scintillating extraction media for separation and measurement of charged-particle-emitting radionuclides in aqueous solutions, Radioact. Radiochem., 11, 34-46 (2000).

35. Egorov, O.B., S.K. Fiskum, M.J. O'Hara, and J.W. Grate, Radionuclide Sensors Based on Chemically Selective Scintillating Microspheres: Renewable Column Sensor for Analysis of 99Tc in Water, Anal. Chem., 71, 5420-5429 (1999).

36. Egorov, O.B., and J.W. Grate, unpublished results. 2002.

37. Bruckner-Lea, C.J., M.S. Stottlemyre, D.A. Holman, J.W. Grate, F.J. Brockman, and D.P. Chandler, Rotating Rod Renewable Microcolumns for Automated, Solid-Phase DNA Hybridization Studies, Anal. Chem., 72, 4135-4141 (2000).

38. Egorov, O., M.J. O'Hara, J.W. Grate, and J. Ruzicka, Sequential Injection Renewable Separation Column Instrument for Automated Sorbent Extraction Separations of Radionuclides, Anal. Chem., 71, 345-352 (1999).

39. Ruzicka, J., and L. Scampavia, From Flow Injection to Bead Injection, Anal. Chem., 71, 257A-263A (1999).

40. Ruzicka, J., Discovering flow injection; journey from sample to live cell and from solution to suspension, Analyst, 119, 1925-1934 (1994).

41. Egorov, O., and J. Ruzicka, Flow injection renewable fiber optic sensor system. Principle and validation on spectrophotometry of chromium(VI), Analyst, 120, 1959-1962 (1995).

42. Heimbuch, A.M., H.Y. Gee, A.J. DeHaan, and L. Leventhall. The Assay of Alpha- and BetaEmitters by Means of Scintillating Ion Exchange Resins. in Radioisotope Sample Measurement Techniques in Medicine and Biology, International Atomic Energy Agency Symposium. 1965. Vienna, May 24-28.

43. Li, M., and J.B. Schlenoff, Ion Exchange Using a Scintillating Polymer With a Charged Surface, Anal. Chem., 66, 824-829 (1994).

44. Dale, C.J., P.E. Warwick, and I.W. Croudace, An optimized method for technetium-99 determination in low level waste by extraction into tri-n-octylamine, Radioact. Radiochem., 7, 23-27 (1996). 
45. Egorov, O.B., M.J. O'Hara, J. Ruzicka, and J.W. Grate, Sequential Injection System with Stopped Flow Radiometric Detection for Automated Analysis of 99Tc in Nuclear Waste, Anal. Chem., 70, 977-984 (1998).

46. Horwitz, E.P., M.L. Dietz, R. Chiarizia, H. Diamond, S.L. Maxwell, and M.R. Nelson, Separation and preconcentration of actinides by extraction chromatography using a supported liquid anion exchanger: application to the characterization of high-level nuclear waste solutions, Anal. Chim. Acta, 310, 63-78 (1995).

47. Nevissi, A.E., M. Silverston, Strebin, R.S., and J.H. Kaye, Radiochemical Determination of Technetium-99, J. Radioanal. Nucl. Chem. Articles, 177, 91-99 (1994).

48. Bonnesen, P.V., G.M. Brown, S.D. Alexandratos, L.B. Bavoux, D.J. Presley, V. Patel, R. Ober, and B.A. Moyer, Development of bifunctional anion-exchange resins with improved selectivity and sorptive kinetics for pertechnetate: Batch-equilibrium experiments, Environmental Science \& Technology, 34, 3761-3766 (2000).

49. Gu, B.H., G.M. Brown, P.V. Bonnesen, L.Y. Liang, B.A. Moyer, R. Ober, and S.D. Alexandratos, Development of novel bifunctional anion exchange resins with improved selectivity for pertechnetate sorption from contaminated groundwater, Environmental Science \& Technology, 34, 1075-1080 (2000).

50. Kawasaki, M., T. Omori, and K. Hasegawa, Adsorption of Pertechnetate on an AnionExchange Resin, Radiochimica Acta, 63, 53-56 (1993).

51. Moyer, B.A., and P.V. Bonnesen, Physical Factors in Anion Separations, in Supramolecular Chemistry of Anions, A. Bianchi, Bowman-James, K., Garcia-Espana, E., Eds. and Editors. 1997, Wiley-VCH: New York. p. 1-44.

52. Reilley, C., G.P. Hildebrand, and J.W. Ashley, Gas Chromatographic Response as a Function of Sample Input Profile, Anal. Chem., 34, 1198-1213 (1962).

53. Wenzel, W., Evaluation of frontal chromatograms, J. Chromatogr. A, 928, 1-12 (2001).

54. Yang, G.L., and Z. Hu, Universal theoretical moment expressions for elution and frontal chromatography of pellicular ion exchange resins, React. Funct. Polym., 31, 25-29 (1996).

55. Lovkvist, P., and J.A. Jonsson, Capacity of Sampling and Preconcentration Columns with a Low Number of Theoretical Plates, Anal. Chem., 59, 818-821 (1987).

56. Lovkvist, P., and J.A. Jonsson, Description of Sample Introduction in Chromatography as a Separate Term in the Mass-Balance Equation, J. Chromatogr., 356, 1-8 (1986).

57. Scudder, K.M., C.H. Pollema, and J. Ruzicka, Fountain cell: a tool for flow based spectroscopies, Anal. Chem., 64, 2657-2660 (1992). 